\title{
Numerical investigation on slender concrete-filled steel tubular columns subjected to biaxial bending
}

\author{
A. Espinós ${ }^{a *}$, V. Albero ${ }^{a}$, M. L. Romero ${ }^{a}$, M. Mund ${ }^{b}$, I. Kleiboemer ${ }^{b}$, P. Meyer ${ }^{b}$ and P. \\ Schaumann ${ }^{\text {b }}$
}

${ }^{a}$ Instituto de Ciencia y Tecnología del Hormigón (ICITECH), Universitat Politècnica de València, Spain

${ }^{b}$ Institute for Steel Construction, Leibniz Universitaet Hannover, Germany

*corresponding author, e-mail address: aespinos@mes.upv.es

\begin{abstract}
The behaviour of concrete-filled steel tubular columns under axial compression or combined compression and uniaxial bending has been deeply investigated in past years by means of experimental testing and numerical simulations. However, the behaviour of these columns under biaxial bending has been scarcely investigated, in fact, a very limited number of experimental tests are available for this loading situation. Additionally, the current provisions in EN1994-1-1 for biaxial bending need to be revised, in order to be aligned with the new methods that are being proposed for the new generation of Eurocodes. This paper presents the outcome of a numerical investigation on the load-bearing capacity of slender concrete-filled steel tubular columns subjected to biaxial bending. The focus is on creating and validating a numerical model for room temperature that can predict the behaviour of this type of columns under biaxial bending, which may be used for evaluating the current design guidelines in EN1994-1-1. The numerical model is validated by comparison against experimental tests from the literature, proving that it predicts the ultimate load of slender columns with good accuracy. Different eccentricities about the minor and major axis and different moment ratios are considered, so that this investigation contains cases for both uniaxial and biaxial bending. With the help of this numerical model, the experimental results are extended to generate more cases, in order to assess the accuracy of the current provisions in EN1994-1-1 for concrete-filled steel tubular columns subjected to biaxial bending.
\end{abstract}

Keywords: Concrete-filled steel tubular columns; biaxial bending; finite element model; Eurocode 4.

\section{Introduction}

In recent years, the usage of concrete-filled steel tubular (CFST) columns has increased, owing to several advantages obtained from combining both materials: high strength and ductility and a high fire resistance without external protection [1]. The performance of these composite columns under axial compression or combined compression and uniaxial bending has been well established through experimental and numerical investigations. However, the behaviour of these columns under biaxial bending has been scarcely investigated, in fact, few experimental tests can be found in the literature for this loading situation.
In this paper, a numerical model is developed for studying the behaviour of slender CFST columns of rectangular section subjected to biaxial bending. The numerical model is validated by comparison with experimental tests on columns subjected to biaxial bending at room temperature [2] and, through the validated numerical model, additional results are generated in order to assess the provisions of EN1994-1-1 [3]. The results of this investigation show that the numerical model can predict the behaviour of these columns in a realistic manner. From the assessment of the method in EN1994$1-1$, it can be affirmed that the standard lays on the safe side, although for certain cases the predictions are too conservative. 


\section{Numerical model}

A three-dimensional finite element model is created by means of the package ABAQUS [4]. The numerical model is composed of four parts: the steel tube, the concrete core and two steel end plates. A full description of the numerical model is given in the following subsections.

\subsection{Finite element mesh}

For the concrete core and the steel tube, linear eight-noded solid elements with reduced integration are used (C3D8R), see Fig. 1. In turn, the steel end plates are meshed with linear 4noded shell elements with reduced integration (S4R). A maximum finite element size of $2 \mathrm{~cm}$ is adopted following the recommendations from Espinos et al. [5]. In the direction of the thickness of the steel tube two elements are used.

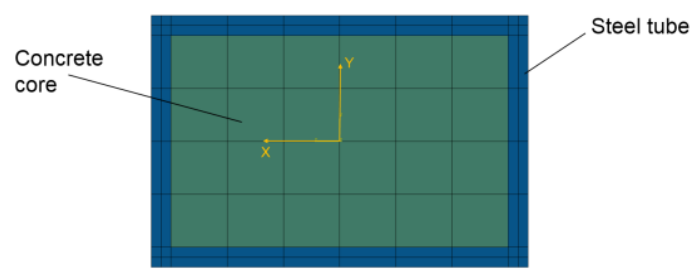

Fig. 1. Mesh of the cross-section.

\subsection{Contact at the steel-concrete interface}

Contact formulations between the steel tube and the concrete core as well as between the plates and the concrete core have to be defined. The contact is modelled with a "Surface-toSurface" interaction. The interaction property describes the tangential and normal behaviour between steel and concrete. The transfer of a force in the normal direction only exists in case of compression. It is defined as "Hard Contact" with the Augmented Lagrange method. In the tangential direction, the Coulomb friction model with a constant friction coefficient $\mu$ of 0.3 is employed. These contact properties are assumed as recommended from previous numerical investigations by the authors [5].

\subsection{Boundary conditions}

At both ends of the column, steel plates are modelled to apply the boundary conditions. These two plates are defined as rigid bodies. All points of the plates are coupled to one reference point, is such a way that the movement of all nodes is the same as that of the reference point. Depending on the eccentricity and the end moment ratio from the cases used for validation, the position of the reference points differ (Fig. 2a). The top end reference point can move freely in axial direction and rotate, while at the reference point located at the bottom end of the column (Fig. 2b), no displacements are allowed and the rotation is permitted. An imposed displacement is applied to the top reference point.
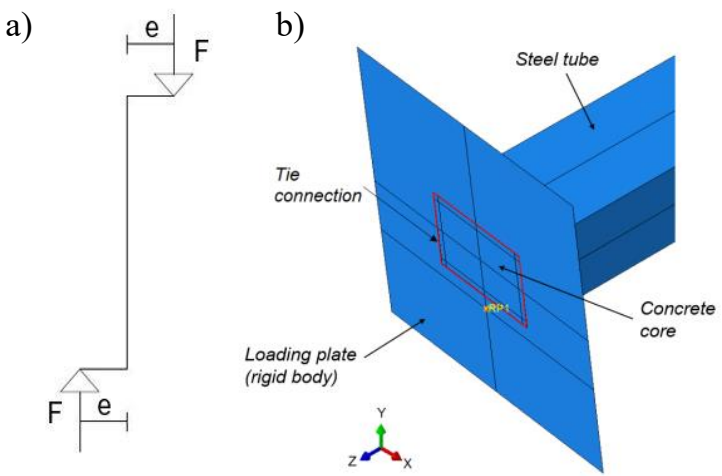

Fig. 2. Boundary conditions: a) loading points, b) details of the bottom end.

\subsection{Initial imperfection}

The initial imperfection should be taken into account to initiate the buckling of the column. For that purpose, a previous eigenmode analysis is carried out in a separate model and afterwards imported into the mechanical model. The first mode is a half-sine wave for buckling about the minor axis (Fig. 3a) and the second about the major axis (Fig. 3b).
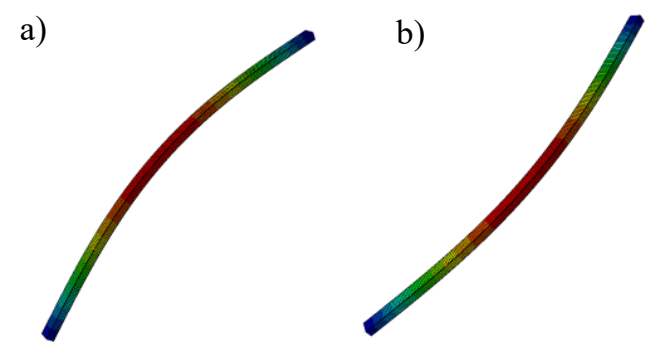

Fig. 3. Initial imperfection: a) eigenmode 1, b) eigenmode 2 .

The initial imperfection is imported into the model and afterwards amplified by a factor of $L / 1000$ as proposed by other authors [5], [6].

\subsection{Steel and concrete material models}

For steel, the isotropic elastic-plastic model based on the data of EN1993-1-1 [7] is used. To define the elastic behaviour of steel, two parameters are needed: The Young's modulus $E$ and the Poisson's ratio $v$. For the description of 
the plastic behaviour, the yield stress and the corresponding plastic strain are defined in ABAQUS [4]. The value of the yield stress is obtained from the data used for the validation of the model.

The elastic behaviour for concrete is also described with the modulus of elasticity and the Poisson's ratio. The values are obtained from Table 3.1 in EN 1992-1-1 [8] and Clause 3.1.3 (4) for uncracked concrete. For defining the plastic behaviour of concrete the threedimensional Concrete Damaged Plasticity (CDP) Model is used in ABAQUS [4]. The input parameters for the plasticity model were selected as previously used by other authors [9], [10] and are described in Table 1.

Table 1. Parameters for CDP model.

\begin{tabular}{ccccc}
\hline $\begin{array}{c}\text { Dilation } \\
\text { Angle }\end{array}$ & Eccentricity & $\mathbf{f}_{\mathbf{b} \mathbf{0}} / \mathbf{f}_{\mathbf{c} 0}$ & $\mathbf{K}$ & $\begin{array}{c}\text { Viscosity } \\
\text { Parameter }\end{array}$ \\
\hline 15 & 0.1 & 1.16 & $2 / 3$ & 0 \\
\hline
\end{tabular}

For the description of the stress-strain relation for compression, the simplified bi-linear approach is used. The strain at reaching the maximum strength and the ultimate strain are obtained of Table 3.1 of EN 1992-1-1 [8].

The tensile behaviour is also described by using the simplification of a bi-linear stressstrain relation. As there is no indication for the ultimate tensile strain of concrete available in the EN 1992-1-1, it is assumed to be four times the elastic tensile strain as recommended in the Model Code CEB-FiB 2010 [11].

\section{Validation}

The numerical model is validated by comparison with experimental tests available in the literature. In particular, the tests carried out by Wang [2] are used for validation. Wang conducted two series of tests on slender columns: eight concrete-filled rectangular hollow steel sections and eight concrete encased columns. In this work only the first group will be considered. The experimental program contained two columns with eccentricities in the minor axis, two with eccentricities in the major axis and four columns subjected to biaxial bending. Also different moment ratios, either 0 (eccentricity only applied at the top end) or -1 (differing directions of the eccentricity at top and bottom end), were applied to the tests to obtain different distributions of the bending moment.
The test data are summarized in Table 2, where the end moment ratios $\left(r=e^{\mathrm{bottom}} / e^{\mathrm{top}}\right)$ and eccentricities are given for both major and minor axis.

The dimensions and the materials of all columns were the same. All specimens were four meters long. The rectangular hollow steel sections were hot-rolled with dimensions of 120 $\mathrm{mm} \times 80 \mathrm{~mm} \times 6.3 \mathrm{~mm}$ and filled with a concrete core without additional reinforcement. This lead to relative slenderness of 1.10 for the major axis and 1.56 for the minor axis. For all the tests, $f_{c}=$ $50 \mathrm{~N} / \mathrm{mm}^{2}, E=37000 \mathrm{~N} / \mathrm{mm}^{2}$ and $f_{y}=370$ $\mathrm{N} / \mathrm{mm}^{2}$.

Table 2. Summary of test data from [2].

\begin{tabular}{|c|c|c|c|c|c|}
\hline \multirow{2}{*}{$\begin{array}{c}\text { Test } \\
\text { no. }\end{array}$} & \multicolumn{2}{|c|}{ Major axis } & \multicolumn{2}{|c|}{ Minor axis } & \multirow{2}{*}{$\begin{array}{l}\text { Test load } \\
(\mathbf{k N})\end{array}$} \\
\hline & $\begin{array}{c}e_{z} \\
(\mathrm{~mm})\end{array}$ & $r_{y}$ & $\begin{array}{c}e_{y} \\
(\mathrm{~mm})\end{array}$ & $r_{z}$ & \\
\hline RHS1 & 0 & - & 55 & -1 & 368 \\
\hline RHS2 & 0 & - & 55 & 0 & 246 \\
\hline RHS3 & 55 & 0 & 110 & 0 & 172 \\
\hline RHS4 & 55 & 0 & 110 & -1 & 238 \\
\hline RHS5 & 55 & -1 & 110 & -1 & 251 \\
\hline RHS6 & 55 & 0 & 55 & 0 & 234 \\
\hline RHS7 & 55 & -1 & 0 & - & 520 \\
\hline RHS8 & 55 & 0 & 0 & - & 480 \\
\hline
\end{tabular}

Fig. 4 shows the deformed shape of one of the columns (RHS3) at the end of the analysis, where the von Mises stress field can be seen.

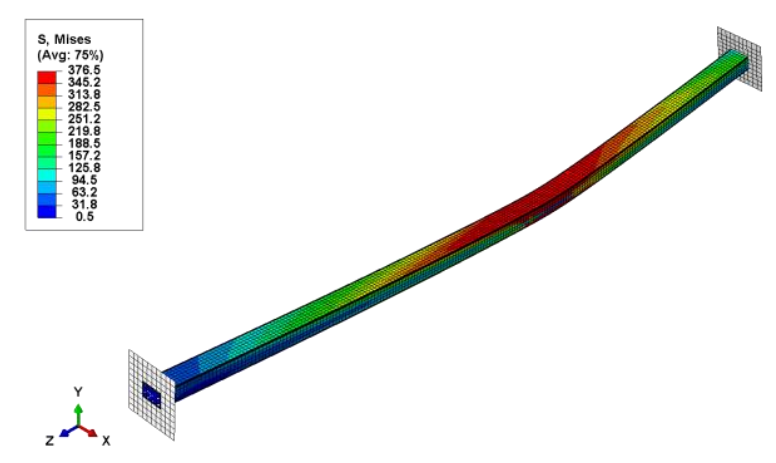

Fig. 4. RHS3 - von Mises stress 3D plot.

The comparison between the forcedisplacement plots, especially in terms of ultimate load and stiffness, are the basis to validate the numerical model. Fig. 5 presents the force-displacement curves for column RHS3, one of the cases with eccentricity applied in both minor and major axis. The numerical results are plotted for both axes (solid lines), together with the measured data from the tests (dashed lines). The displacement in the minor axis is shown by red lines, while the major axis displacement is given by the blue lines. 


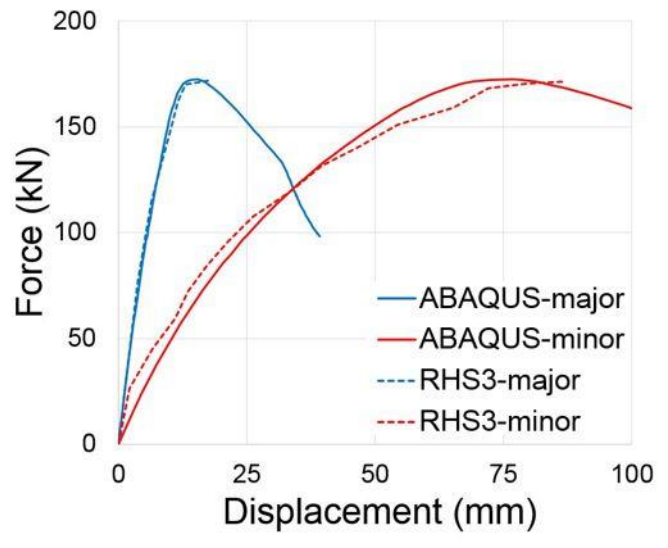

Fig. 5. Force-displacement curves for RHS3.

The numerical calculations predict the behaviour of the column with good accuracy, as can be seen in Fig. 5. The ultimate load and the corresponding displacement at peak load are well captured. The slopes of the ascending branches are also in good agreement.

In order to obtain an overview of the results from the numerical analyses, a diagram is plotted in Fig. 6, in which a comparison between the ultimate loads, calculated and measured, is given.

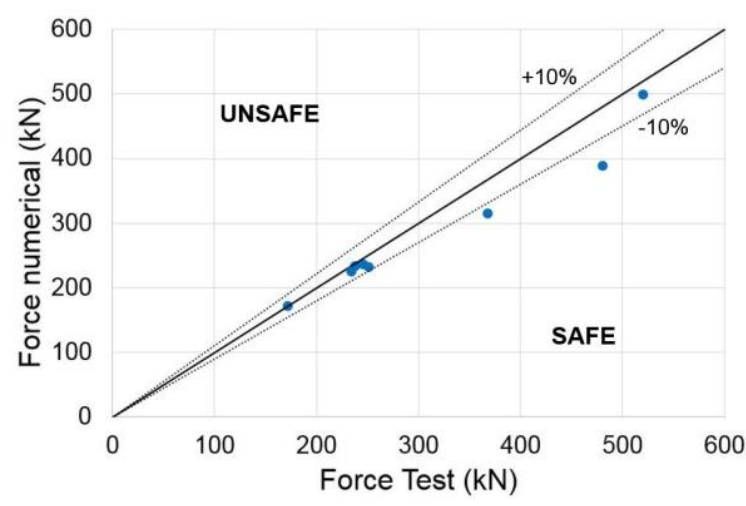

Fig. 6. Comparison between experimental and numerical ultimate load.

From this figure, it is proved that the behaviour of rectangular CFST columns under biaxial bending can be predicted with good accuracy by means of the numerical model. The average error, defined as the test load divided by the numerical load is 1.055 , indicating that the model is well validated. This validation covers various eccentricities and different end moment ratios, as well as uniaxial and biaxial cases.

\section{Assessment of Eurocode 4}

In this section, the simplified design method in Clause 6.7.3.7 of EN1994-1-1 [3] is assessed.
According to this clause, equations (1), (2) and (3) should be satisfied for the stability check in columns subjected to combined compression and biaxial bending.

$\frac{M_{\mathrm{y}, \mathrm{Ed}}}{\mu_{\mathrm{dy}} M_{\mathrm{pl}, \mathrm{y}, \mathrm{Rd}}} \leq \alpha_{\mathrm{M}, \mathrm{y}}$

$\frac{M_{\mathrm{z}, \mathrm{Ed}}}{\mu_{\mathrm{dz}} M_{\mathrm{pl}, \mathrm{z}, \mathrm{Rd}}} \leq \alpha_{\mathrm{M}, \mathrm{z}}$

$\frac{M_{\mathrm{y}, \mathrm{Ed}}}{\mu_{\mathrm{dy}} M_{\mathrm{pl}, \mathrm{y}, \mathrm{Rd}}}+\frac{M_{\mathrm{z}, \mathrm{Ed}}}{\mu_{\mathrm{dz}} M_{\mathrm{pl}, \mathrm{z}, \mathrm{Rd}}} \leq 1,0$

For steel grades between S235 and S355, the coefficient $\alpha_{\mathrm{M}}$ should be taken as 0.9 .

The applied bending moments for each axis are the numerators of the equations. In this evaluation, the ultimate moments obtained from the tests or numerical simulations are used, which are calculated as the ultimate load multiplied by the applied eccentricity on each axis, taking into account the second order effects and imperfections according to Clause 6.7.3.4. In the denominator of the equations appear the factors $\mu$ and the plastic bending resistances for each axis, which are calculated analytically using the methods from the standard. It requires the construction of the interaction curve for each axis, which is done following Clause 6.7.3.2(5). Fig. 7 shows an example of the interaction diagrams for the cases used for validation.

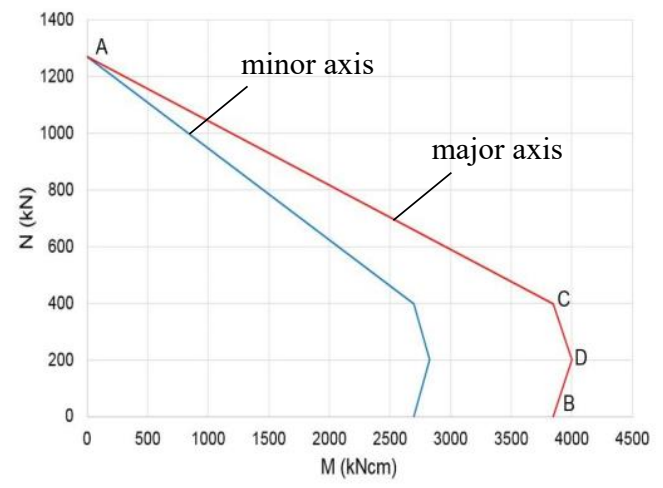

Fig. 7. Interaction diagram for both axes.

The $\mu$ values are obtained as follows: first, the applied normal force is taken from the ultimate load obtained in the test or numerical simulations. Afterwards, the corresponding plastic bending resistances predicted by EN 1994-1-1 on each axis $M_{\mathrm{pl}, \mathrm{y}, \mathrm{N}, \mathrm{Rd}}$ and $M_{\mathrm{pl}, \mathrm{zN}, \mathrm{Rd}}$ are obtained by intersecting the corresponding 
interaction diagram at this axial load level. Finally, this moments divided by the plastic bending resistances $\left(M_{\mathrm{pl}, \mathrm{y}, \mathrm{Rd}}\right.$ and $\left.M_{\mathrm{pl}, \mathrm{R}, \mathrm{Rd}}\right)$ give the values of $\mu_{\mathrm{dy}}, \mu_{\mathrm{dz}}$.

$$
\mu_{\mathrm{dy}}=\frac{M_{\mathrm{pl}, \mathrm{y}, \mathrm{N}, \mathrm{Rd}}}{M_{\mathrm{pl}, \mathrm{y}, \mathrm{Rd}}}, \mu_{\mathrm{dz}}=\frac{M_{\mathrm{pl}, \mathrm{z}, \mathrm{N}, \mathrm{Rd}}}{M_{\mathrm{pl}, \mathrm{z}, \mathrm{Rd}}}
$$

For carrying out the assessment of the method, the applied bending moment needs to be calculated. It is the multiplication of the axial load $N_{\text {Ed }}$, which is obtained from the test or numerical model, the applied eccentricity $\left(e_{z}\right.$ or $e_{y}$ ) and a moment magnification factor $k$ which considers the second order effects, as given in Clause 6.7.3.4(5):

$$
\begin{aligned}
& M_{\mathrm{y}, \mathrm{Ed}}=N_{\mathrm{Ed}} \cdot e_{z} \cdot k_{y} \\
& M_{\mathrm{z}, \mathrm{Ed}}=N_{\mathrm{Ed}} \cdot e_{y} \cdot k_{z} \\
& k_{y}=\frac{\beta_{y}}{1-\frac{N_{\mathrm{Ed}}}{N_{\mathrm{cr}, \mathrm{eff}}}} ; \quad k_{z}=\frac{\beta_{z}}{1-\frac{N_{\mathrm{Ed}}}{N_{\mathrm{cr}, \mathrm{eff}}}}
\end{aligned}
$$

Imperfections are also considered in the plane in which failure is expected to occur, or if it is not evident which plane is the most critical, checks are made for both planes. This includes another term to be added to equations (5) and (6), which is $N_{\mathrm{Ed}} \cdot e_{\text {imp }} \cdot k^{\prime}$. The member imperfection is taken from Table 6.5 in EN1994-1-1 [3], being $L / 300$ for RHS sections without reinforcement as in this case.

Factors $\beta$ for evaluating $k_{y}, k_{z}$ and $k^{\prime}$ are obtained from Table 6.4 in the same code, depending on the end moment ratio and moment distribution. In this case, for the member imperfection, a parabolic distribution of moments is considered $(\beta=1)$, while for the applied eccentricity a linear distribution of moment is considered:

$$
\beta=0.66+0.44 r \text { but } \beta \geq 0.44
$$

In order to evaluate the accuracy of the described method from EN1994-1-1, the previously described tests from Wang [2] are used as reference in this section. Since the number of tests is very limited and only end moment ratios $r=0$ and $r=-1$ are included in this experimental campaign, the numerical model is used for generating more cases covering other end moment distributions $(r=1)$. The new cases are generated from column specimens RHS1, RHS3, RHS6 and RHS7 by varying the major and minor axis eccentricities in the numerical model (see columns RHS $1 b$ to RHS7c in Table 3). In this table, the data of the relative eccentricity applied on each axis $\left(e_{z} / H\right.$, $\left.e_{y} / B\right)$ and end moment ratios $\left(r_{y}, r_{z}\right)$ are given for each of the columns analysed. The last column

\begin{tabular}{|c|c|c|c|c|c|}
\hline \multirow{2}{*}{$\begin{array}{c}\text { Column } \\
\text { no. }\end{array}$} & \multicolumn{2}{|c|}{ Major axis } & \multicolumn{2}{|c|}{ Minor axis } & \multirow{2}{*}{$\begin{array}{c}\boldsymbol{M}_{E d, z} / \boldsymbol{M}_{p l, z, N d} \boldsymbol{R d} \\
+ \\
\boldsymbol{M}_{E d, y} / \boldsymbol{M}_{p l, y, N, R d}\end{array}$} \\
\hline & $\boldsymbol{e}_{z} / \boldsymbol{H}$ & $r_{y}$ & $e_{y} / B$ & $r_{z}$ & \\
\hline RHS1 & 0 & - & 0,69 & -1 & 0,99 \\
\hline RHS2 & 0 & - & 0,69 & 0 & 2,64 \\
\hline RHS3 & 0,46 & 0 & 1,38 & 0 & 1,59 \\
\hline RHS4 & 0,46 & 0 & 1,38 & -1 & 3,16 \\
\hline RHS5 & 0,46 & -1 & 1,38 & -1 & 4,10 \\
\hline RHS6 & 0,46 & 0 & 0,69 & 0 & 2,44 \\
\hline RHS7 & 0,46 & -1 & 0 & - & 1,65 \\
\hline RHS8 & 0,46 & 0 & 0 & - & 1,72 \\
\hline RHS1b & 0 & - & 0,69 & 1 & 1,40 \\
\hline RHS1c & 0 & - & 1,38 & 1 & 1,25 \\
\hline RHS3b & 0,46 & 1 & 1,38 & 1 & 1,41 \\
\hline RHS3c & 0,92 & 1 & 1,38 & 1 & 1,44 \\
\hline RHS6b & 0,46 & 1 & 0,69 & 1 & 1,54 \\
\hline RHS6c & 0,92 & 1 & 0,69 & 1 & 1,34 \\
\hline RHS7b & 0,46 & 1 & 0 & - & 2,52 \\
\hline RHS7c & 0,92 & 1 & 0 & - & 1,41 \\
\hline
\end{tabular}
of the table summarizes the result of the application of the stability check in equation (3).

Table 3. Results of the assessment of the method from EN1994-1-1.

It can be seen that all the values of the stability check in Table 3 are higher than 1 (or 0,9 in the uniaxial cases), meaning that the ultimate bending moment corresponding to the test or numerical load is higher than the maximum one predicted by EN1994-1-1, thus the method is conservative.

For constant bending moment $(r=1)$, the results give reasonable predictions on the safe side (columns RHS1b to RHS7c), while for variable bending moment ( $r=0$ and $r=-1$ ) it can be observed that the results are overly conservative, especially if at any of the axes is applied a moment ratio of -1 (RHS4 or RHS5). The reason behind this greater deviation may be the limitation of $\beta$ to 0.44 (see equation 8 ), when for an end moment ratio of $r=-1, \beta=0.22$. The results would be more accurate in these cases without the limitation of $\beta$. Therefore, it is recommended that the method in EN1994-1-1 is revised for the situation of variable bending moment distribution. Due to the small number of cases compared in this paper, this matter is proposed for being investigated in future work. 


\section{Conclusions}

This paper presented a numerical model which describes the behaviour of slender concrete-filled steel tubular columns subjected to biaxial bending in a realistic manner. The described model was proved to be able to predict the ultimate load in a good accuracy, after being validated against eight tests available in the literature. Different eccentricities about the minor and major axis and different end moment ratios were considered, so that the tests contained cases covering both uniaxial and biaxial bending as well as constant and variable bending moment along the column.

The current design guidelines in EN1994-1-1 for biaxial bending were evaluated with the help of both test results from the literature and additional cases generated by means of the numerical model. The $\mathrm{M}-\mathrm{N}$ interaction diagrams were built up in both planes and the stability check was applied for each column specimen as given in Clause 6.7.3.7. This evaluation proved that the current design guidelines in Eurocode 4 lay on the safe side, however leading to quite high deviations for columns with different eccentricities applied at both ends (variable bending moment). Especially for columns with end moment ratio of -1 , the predictions of EN1994-1-1 were too conservative, therefore it is proposed that the situation of variable bending moment is revised in further investigations.

\section{Acknowledgements}

The authors would like to express their sincere gratitude to the "Conselleria d'Educació, Investigació, Cultura i Esport" of the Valencian Community (Spain) for the help provided through the project GV/2017/026.

\section{References}

[1] Han LH, Li W, Bjorhovde R. Developments and advanced applications of concrete-filled steel tubular (CFST) structures: Members. Journal of Constructional Steel Research 2014; 100: 211228.

[2] Wang YC. Tests on slender composite columns. Journal of Constructional Steel Research 1999; 49: 25-41.

[3] EN 1994-1-1. Eurocode 4. Design of composite steel and concrete structures. Part 1-1: General rules and rules for buildings. Brussels (Belgium): Comité Européen de Normalisation (CEN); 2004.

[4] ABAQUS. ABAQUS/standard version 6.14 user's manual. Dassault Systèmes, USA.

[5] Espinos A, Romero ML, Hospitaler A. Advanced model for predicting the fire response of concrete filled tubular columns. Journal of Constructional Steel Research 2010; 66: 1030-1046.

[6] Patel VI, Liang QQ, Hadi MNS. Nonlinear analysis of biaxially loaded rectangular concretefilled stainless steel tubular slender beamcolumns. Engineering Structures 2017; 140: 120 133.

[7] EN 1993-1-1. Eurocode 3. Design of steel structures. Part 1-1: General rules and rules for buildings. Brussels (Belgium): Comité Européen de Normalisation (CEN); 2005.

[8] EN 1992-1-1. Eurocode 2. Design of concrete structures. Part 1-1: General rules and rules for buildings. Brussels (Belgium): Comité Européen de Normalisation (CEN); 2004.

[9] Albero V, Espinos A, Romero ML, Hospitaler A, Bihina G, Renaud C. Proposal of a new method in EN1994-1-2 for the fire design of concretefilled steel tubular columns. Engineering Structures 2016; 128: 237-255.

[10] Sümer Y, Aktas M. Defining parameters for concrete damage plasticity model. Challenge Journal of Structural Mechanics 1 2015; pp.146155.

[11]FIB. Model Code 2010 (Volume 1). Lausanne, Switzerland. 